\title{
Determinants of coffee market supply: The case of Yirgachefe district, Gedeo zone, southern Ethiopia
}

\author{
Tizazu Toma Dilebo
}

Coordinator of Regional Socio-Economics Researches, Southern Agricultural Research Institute, Hawassa, Ethiopia.

E-mail: tomatizazu@yahoo.com. Tel: +251916860111.

Accepted $24^{\text {th }}$ April, 2019.

\begin{abstract}
Coffee produced in Yirgachefe District had been internationally known as the rarest and most prized coffee. But Yirgacheffe district's agriculture bureau complains that the current supply is less that the potential of the district. These might be due to some socio-economic and demographic factors. Thus this study was conducted with the objective of identifying these factors. To achieve this objectives, data were collected from 150 farm households, 30 experts and from different published and unpublished sources. The data collected were analyzed using descriptive statistics and econometric model (multiple linear regression model). The study result showed that 5 variables were found to be significantly affecting market supply of coffee at households' level. These were, education level of household heads, land covered by coffee, experience in coffee production and marketing, cost of coffee production and credit use. The study indicated the need to expand formal education in the district, provide regular experience sharing program, subsidize coffee production, and arrange credit facility for coffee production.
\end{abstract}

Keywords: Coffee, determinants, households, market supply.

\section{INTRODUCTION}

Coffee is produced in more than 50 developing countries in Latin America, Africa, and Asia and it is an important source of income for 20 to 25 million families worldwide, 80 percent of whom are smallholder farmers (World Bank, 2004; Murphy and Dowding, 2015; TECHNOSERVE, 2017). It is the second most traded commodity in the world after oil (Roldán, 2007; Joshi, 2017). As per Panhuysen and Pierrot (2014), it engages over 100 million people in its producing and processing. While coffee is grown in more than 50 countries, according to TECHNOSERVE (2017) almost two-thirds of all production is concentrated in just four countries: Brazil, Vietnam, Colombia, and Indonesia.

Ethiopia, the birth place of coffee, stands first in coffee production in Africa and is the fifth largest coffee producer in the world next to Brazil, Vietnam, Colombia, and Indonesia, contributing about 4.2 percent of total world coffee production (Abiy, 2016). By 2011/12, the country had produced approximately 500,000 metric tons of coffee. Out of nine regional states of Ethiopia, coffee is dominantly produced in Oromia national regional state and Southern Nation, Nationalities and People regional state. As per the regional coffee, tea and spices authority (CTSA, 2018), south nations, nationalities and peoples regional state contributes around $60 \%$ of the total washed coffee and around $40 \%$ of the total unwashed coffee being supplied to domestic and international markets. Sidama and Gedeo zones are the first and the second highest producers of coffee in SNNPR. Yirgachefe district is one of the six districts of Gedeo zone and is the highest producer of coffee in the Zone. It contributed around $32.1 \%$ of the total washed coffee and around $26.4 \%$ of the total unwashed coffee produced in the Zone in 2017. The total annual production of coffee in 2017 was 70546 qt which was around $30.1 \%$ of the total coffee produced in the zone in 2017 which is 234061 qt. 
However, as per the district Coffee and spices authority, the current supply of coffee from the study district is low compared to the potential of the district and is also low compared to the efforts made by various governmental and non-governmental organizations. This might be due to some demographic and socio-economic factors than hindered supply of coffee.

Therefore, this study was intended to identify those demographic and socio-economic constraints that determined market supply of coffee in Yirgachefe district.

\section{METHODOLOGY}

\section{Description of the study area}

Yirgachefe district is one of the 6 district of Gedeo zone which is located at the east-central part of Gedeo zone at a distance of $37 \mathrm{~km}$ from the capital city of the Zone, Dila and at $127 \mathrm{~km}$ from the capital of SNNPR, Hawassa. Astronomically it is situated in the coordinates of $6^{\circ} 06^{\prime}$ to latitude and $38^{\circ} 09^{\prime}$ to $38^{\circ} 31^{\prime}$ 'East longitudes. The total area of the District was 266 sq.km and it was $6^{\circ} 29^{\prime}$ North bordered on the south by Kochere, on the west by the Oromia region, on the north by Wenago, on the east by Bule, and on the southeast by Gedeb (SNNPR BoFED, 2012).

There were around 246,573 people in the District who live being clustered in 36 Peasant associations, out of which $50.3 \%$ (123997) were females and the rest $49.7 \%$ (122576) were males as per the 2013 projection of Central Statistics Agency (CSA, 2013) for the coming 4 years from 2014-2017. The total household size was estimated to be 41096 . Around $87 \%(214,439)$ of the total population are living in rural areas depending on crop production and livestock raising and the rest 13\% (32134) are dwellers in the urban part of the District.

The average population density is estimated to be 933 persons per square kilometer and the average land holding size of the District is around 0.65 hectare, which is much below the national average of total households' land holding in rural areas (1.77 hectares) (CSA and World Bank, 2013). Agro-ecologically, the District exhibits 93\% Weina Dega (Midland) and 7\% Dega (Highland). It has a mean annual temperature ranging from 15.1 to $20^{\circ} \mathrm{C}$, elevation ranging from 1501 to 3000 meter above sea level and average annual rainfall ranging from 1201 to $1800 \mathrm{~mm}$ (District's BoFED, 2015).

Regarding coffee production, the District was ranked as highest producer of coffee in Gedeo zone as out of the total 36 peasant associations of the district, 33 were coffee producer peasant association s. Of this amount, 26 are registered as high producer peasant association s. The total annual production for the year 2016 was 49464 quintals of washed coffee and 21082 quintals of unwashed coffee according to the reports of Yirgachefe coffee, tea and spices production coordination department (CTSPCD, 2017). Figure 1 shows a map of
Yirgachefe district.

\section{Data types, sources and method of data collection}

Both primary and secondary data were used to conduct this study. Primary data were collected from 50 coffee producer farmers and 16 agriculture experts working in Yirgachefe district. Secondary data were collected from different organizational reports and documents, and from different published and unpublished sources. Data have been collected from primary data sources using data collection instruments such as observation, pre-tested semi structured questionnaire and check lists. During observation, availability of coffee farm, the farming system, supply materials and farm tools used have been observed. Check lists were used to collect data from agricultural experts working in the study District to have the overall outlook on the production and marketing of coffee in the study district. Interview method has been employed to collect data from farmers using pre-tested semi-structured separate questionnaires.

\section{Sample size determination and sampling method}

Regarding sample size, 50 producers and 16 agriculture exporters were arbitrarily used as samples for this particular study due to time and budgetary constraints. Random sampling method was used to select producer farmers from 3 peasant associations of Yirgachefe district. These peasant associations were, konga, Adame and Wegide. All 16 experts were randomly selected as samples for this study.

\section{Method of data analysis}

The data collected was analyzed using descriptive statistics and econometric model (multiple linear regression model).Descriptive statistics such as mean, standard deviations and frequency tables were employed to summarize the socio-economic and demographic characteristics related to sample respondents. The econometric model (multiple linear regression model) was used to analyze determinants of market supply of coffee at households' level. As stated in Tizazu et al. (2017), the multiple linear regression model was specified as $Y$ (market supply of coffee) $=f($ sex, education, family size, land size covered by coffee, experience, lag price, total cost, seed, credit use, extension contact). The estimated coefficients indicate the amount of change in the dependent variable due to a unit change in the independent variables. In matrix form, the supply function can be specified as:

$Y=\beta X+U$ 


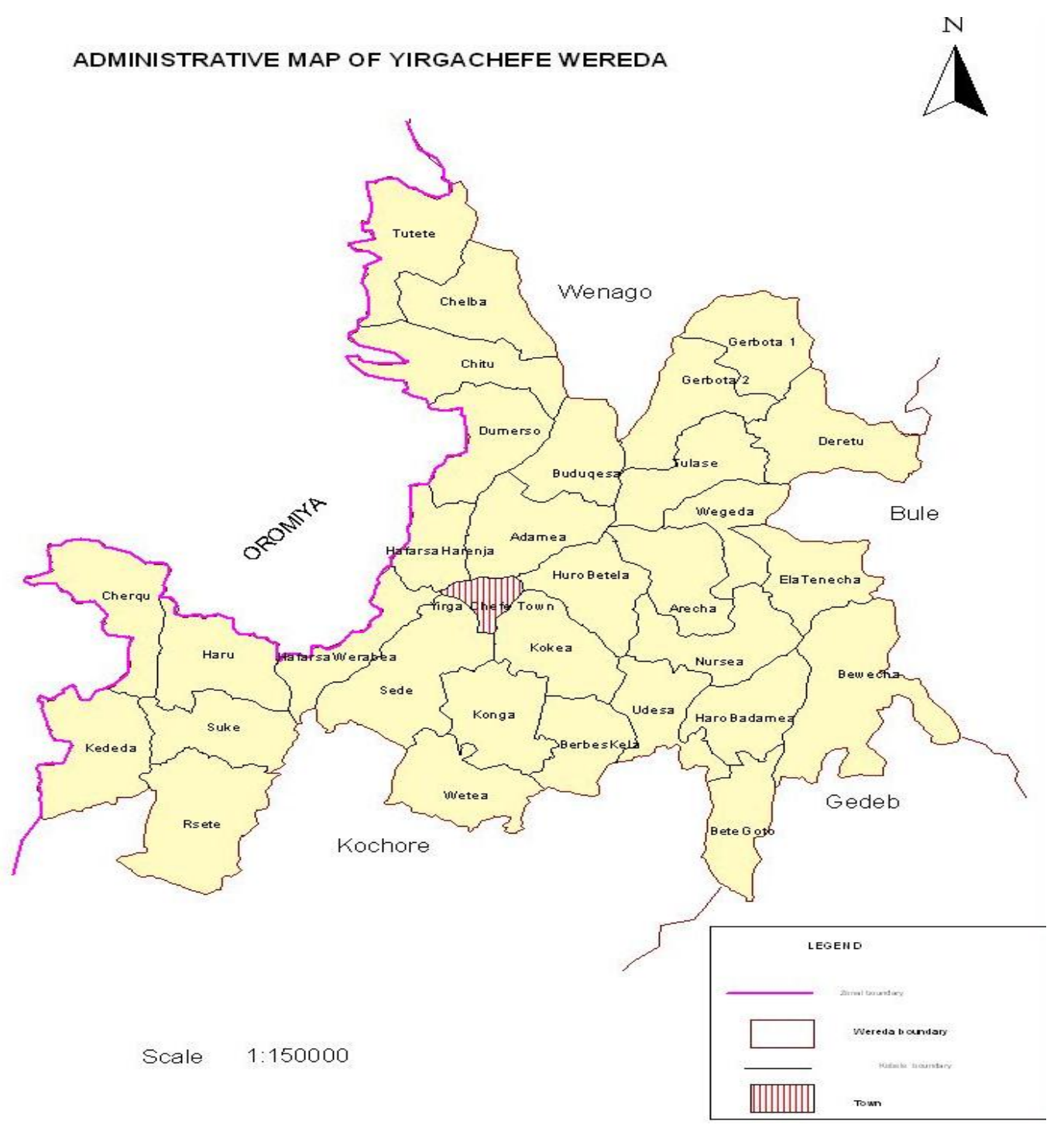

Figure 1. Map of Yirgachefe District. Source: BOFED (2017).

Where, $Y=$ the volume of coffee supplied to the market

$\beta=a$ vector of estimated coefficient of the explanatory variables

$X=$ a vector of explanatory variables

$U=$ Disturbance term

STATA computer program was employed to analyze the data. Omitted variable and heteroscedasticity detection tests were conducted in STATA using Ramsey test and Breusch-Pagan (BP) test respectively. Variance Inflation Factor (VIF) was employed to test the existence of Multi co-linearity problem among explanatory variables.

\section{Definition, measurement and hypothesis of study variables}

\section{Dependent variable}

The dependent variable in this study is market supply of coffee and it is in natural logarithm (In) form. It is a continuous variable representing actual volume of coffee supplied in 2017/18 production year by individual households to the market and measured in quintal.

\section{Independent variables}

These were explanatory variables expected to influence the dependent variable. Some of them were continues, some were discrete and some others were dummy. They include sex of the household head, experience in coffee production and marketing (years), family size (EMU), education level of household heads (grade), land covered by coffee (hectare), lag price (birr), number of days of extension contact, credit use, total cost $(\mathrm{In})$ and the type of seed used. Their category, measurement unit and expected effect on the dependent variable are all discussed in Table 1. 
Table 1. Definition, measurement and hypothesis (expected effect) of study variables.

\begin{tabular}{llll}
\hline Variables & Category & Measurement & Expected effect \\
\hline Volume of coffee supplied to the market (Dependent) & Continuous & Quintals & \\
Sex of household head & Dummy & 1 -if male ; 0-otherwise & + \\
Education & Discrete & Grades & + \\
Experience & Continuous & Years & + \\
Family size & Discrete & Equivalent man unit & + \\
Lag price & Continuous & Birr & + \\
Total cost (In) & Continuous & Birr & - \\
The type of seed used & Dummy & 1 -if improved ; 0-if local & + \\
Credit use & Dummy & 1 -if used ; 0-otherwise & + \\
Land covered by coffee & Continuous & Hectares & + \\
Extension contact & Discrete & Number of days & + \\
\hline
\end{tabular}

Table 2. Distribution of respondents by sex, type of seed used and credit use.

\begin{tabular}{llcc}
\hline Variables & & Frequency & Percent \\
\hline \multirow{2}{*}{ Sex of respondent } & Female & 7 & 14.0 \\
& Male & 43 & 86.0 \\
\multirow{2}{*}{ The type of seed used } & Local & 14 & 28 \\
& Improved & 36 & 72 \\
\multirow{2}{*}{ Credit use } & Not used & 45 & 90 \\
& Used & 5 & 10 \\
\hline
\end{tabular}

Source: Survey result, 2017/2018

\section{RESULTS AND DISCUSSION}

\section{Demographic and socio economic characteristics of respondents}

\section{Sex, the type of seed used and credit use}

The study result indicated that $86 \%$ of the total respondents were male headed households and the rest $14 \%$ of the respondents were female headed households. Most of the respondents (72\%) used improved seed and the rest $28 \%$ used local seeds on their farmlands. Of all the respondents, only $10 \%$ used credit and the rest $90 \%$ did not get credit for coffee production (Table 2).

\section{Age, education level, family size and experience in coffee market supply}

The mean age of respondents was around 47 years with minimum age of 26 and maximum of 70 . The mean education level of respondents was around grade 7 . There were respondents who were unable of reading and writing (illiterate). There were also respondents who were college graduates. Regarding family size, the mean family size was 10 with minimum and maximum family sizes of 4 and 19 respectively. The minimum experience in coffee production and marketing was 4 years and the maximum was 45 years with mean experience of around 21 years. Concerning extension contact, the minimum frequency of contact was 1 day per year. The maximum was 10 days per year with mean contact days of around 4 per year (Table 3 ).

\section{Total land holding, land covered by coffee and total production}

Regarding land holding, the minimum land holding of respondents was 0.5 ha and the maximum was 7.6 ha with mean land holding of 3.27 ha. The mean land size covered by coffee was 2.53 ha with minimum and maximum land size of 0.3 ha and maximum of 6ha. Regarding total production of coffee, the mean production was 118 qt with minimum amount of 20 ha and maximum of 820 qt (Table 4). The standard deviation result indicated that there was high variability among producers in their amount of production.

\section{Total production cost and unit cost per quintal}

Total production cost in this study refers to variable costs including cost of seed purchase, labor cost, compost 
Table 3. Distribution of respondents by age, education level, family size, experience and extension contact.

\begin{tabular}{lcccc}
\hline Variables & Minimum & Maximum & Mean & Std. Deviation \\
\hline Age & 26 & 70 & 46.62 & 9.56 \\
Education level (grade) & 0 & 15 & 6.56 & 2.93 \\
Family size & 4 & 19 & 10.4 & 3.34 \\
Experience & 4 & 45 & 24.8 & 9.73 \\
No. of extension contact & 1 & 10 & 3.56 & 2.3 \\
\hline
\end{tabular}

Source: survey result, 2017/2018.

Table 4. Distribution of respondents by total land holding, land covered by coffee and total production.

\begin{tabular}{lcccc}
\hline Variables & Minimum & Maximum & Mean & Std. Deviation \\
\hline Total land holding & 0.5 & 7.6 & 3.27 & 1.66 \\
Land covered by coffee & 0.3 & 6 & 2.53 & 1.48 \\
Total production $(\mathrm{qt})$ & 9 & 820 & 118.04 & 193.2 \\
\hline
\end{tabular}

Source: survey result, 2017/2018.

preparation cost and bed preparation costs. The mean total cost of production was birr 32943 with maximum cost of birr 90000 and minimum cost of birr 2900. The mean cost per unit of quintal was birr 634.76 with minimum unit cost of birr 70.12 and maximum of birr 3535 (Table 5).

\section{Determinants of coffee market supply in Yirgachefe district}

Yirgachefe is internationally known in its good flavor coffee. According to Tehsale (2017), the washed coffee of Yirgacheffe is the most famous washed Ethiopian coffee, especially in the United States (as a trademark). It has a test of Blueberry overtones and aroma, with a hint of floralness and wineyness in the finish. Farmers are also good suppliers of coffee. All the coffee produced in Yirgachefe district in 2018 was fully supplied to the market. However, the supply was low compared to the potential of the area and efforts made by GOs and NGOs to increase the supply.

Variables expected to determine market supply of coffee in the study district were hypothesized. All the hypothesized explanatory variables were checked for the existence of multi-co linearity, heteroscedasticity and omitted variables problems (appendix). Variance inflation factor was analyzed to investigate the degree of multi-co linearity among explanatory variables. The results for all VIF values were ranging between 1.29 and 3.02. The mean VIF value was 1.91 . Hence, multi-co linearity was not a serious problem among explanatory variables. Heteroscedasticity was tested for all variables by running Breusch-Pagan/Cook-Weisberg test for heteroscedasticity using STATA computer program. The result indicated that there was no problem of heteroscedasticity in the model. The existence of omitted variables was also checked by using Ramsey Reset test. The result showed that there was no omitted variables problem (appendix). The overall goodness of fit of the regression model was measured by the coefficient of determination (R2). It tells us what proportion of the variation in the dependent variable was explained by the explanatory variables.

Ten explanatory variables were hypothesized to determine market supply of coffee at households' level. These variables were sex of the household head, education level of the household head, experience in coffee market supply, lag price of coffee, credit use, family size, type of seed used, total production cost, land size covered by coffee and number of days of extension contact. Among these hypothesized 10 variables, five variables, namely education level of household head, land covered by coffee, credit use, cost of production and experience in coffee market supply were found to be significantly affecting the households' market supply of coffee (Table 6). The remaining five variables, namely sex of household head, family size, lag price, the type of seed used and extension contact were found to have no significant effect on marketed supply of coffee at households' level.

\section{Education level of respondents}

The model result in table 5 above indicated that education level of respondents affected the volume of coffee supplied to the market positively and significantly at $5 \%$ significant level. The result indicated that holding other things constant (citrus-paribus), as education increases by 1 grade, the volume of coffee supplied to market increases by around $8 \%$. The justification is that as households are educated more and more, they will be more ready to adopt improved technology in coffee 
Table 5. Distribution of respondents by total production cost and cost of 1 quintal of coffee.

\begin{tabular}{lcccc}
\hline Variables & Minimum & Maximum & Mean & Std. Deviation \\
\hline Total cost of production & 2900 & 90000 & 32943 & 27686.07 \\
Cost per a unit of quintal & 700.12 & 3535 & 634.76 & 706.32 \\
\hline
\end{tabular}

Source: survey result $(2017 / 18)$.

Table 6. Determinants of coffee market supply in Yirgachefe district.

\begin{tabular}{lccc}
\hline Variables & Coefficients & Std. error & t-value \\
\hline Sex & 0.0288 & 0.3148 & 0.09 \\
Education & $0.0796^{* \star}$ & 0.0391 & 2.03 \\
Family size & 0.0426 & 0.0431 & 0.99 \\
Land covered by coffee & $0.7093^{\star * *}$ & 0.0722 & 9.83 \\
Experience & $0.0249^{*}$ & 0.0147 & 1.69 \\
Type of seed used & 0.3702 & 0.2567 & 1.44 \\
Lag price & 0.0222 & 0.0357 & 0.62 \\
Cost of production (In) & $-0.4772^{* \star *}$ & 0.0962 & 5.15 \\
Credit use & $0.6547^{* * *}$ & 0.2618 & 2.5 \\
Extension contact & 0.0181 & 0.0519 & 0.35 \\
Constant & $1.8461^{* *}$ & 0.7981 & 2.31 \\
\hline
\end{tabular}

Dependent variable $=$ volume of coffee supplied to the market in 2017/2018 (In), N=50, RSquared $=0.787$, Adjusted R squared $=0.745$. The ${ }^{* \star \star},{ }^{* *}$ and ${ }^{* *}$ show statistically significant variables at $1 \%, 5 \%$ and $10 \%$ respectively.

production and productivity. This will in turn increases total production and then market supply.

\section{Land covered by coffee}

Land covered by coffee affected market supply of coffee positively and significantly as expected. It affected the volume of coffee supplied to the market at $1 \%$ significance level as discussed in table 5 above. The model result showed that as land covered by coffee increased by 1 ha, the volume of coffee supplied to the market increases by $70.93 \%$. It is a known fact that as land size increases, the total amount of production increases and then market supply increases.

\section{Cost of production}

As discussed in Table 6, a unit cost of production affected the volume of coffee supplied to the market significantly as expected. It affected market supply negatively at $1 \%$ significance level. The multiple linear regression model predicted that as unit cost of production increases by $1 \%$, the volume of coffee supplied to the market reduces by $47.72 \%$. The reason might be that as cost increases, farmers refuse to produce coffee and may shift to other crops that can enable to earn better revenue comparatively. Due to this, production reduces and then supply will get lower.

\section{Experience in coffee production and marketing}

Experience in coffee production and marketing is another variable affecting market supply of coffee significantly as expected. It affected the volume of coffee supplied to the market positively at $10 \%$ significance level. The model result in Table 5 indicated that as experience in coffee production and marketing increases by 1 year, the volume of coffee supplied to the market increases by $2.5 \%$. This might be due to the fact that as farmers get more and more experience in their work, production per unit area (productivity) increases and this will have a probability of increasing market supply.

\section{Credit use}

Credit use was also a variable affected the volume of coffee supplied to the market significantly as expected. It affected market supply positively at $1 \%$ significance level as discussed in table 5 above. The model result indicated that compared to those households who did not use credit to produce and supply coffee, the volume of coffee supplied to the market increases by $65.5 \%$ for those who use credit. The justification is that as farmers get credit to produce coffee, they will be able of purchasing renting various inputs such as ox to plough, additional rental land, labor to manual operations and the likes. This is supposed to increase total production and then amount supplied to the market. 


\section{CONCLUSION}

Four variables were found to be significantly affecting the volume of coffee supplied at households' level in Yirgachefe district of Gedeo zone. These variables were education level of the household head, credit use, land covered by coffee, and experience in coffee production and marketing. The economic model result predicted that the volume of coffee supplied to the market for those households who used credit increased by $91.32 \%$ compared to those households who did not; an increase in 1 year formal education increases the volume of coffee supplied by $8 \%$; a year increase in experience of coffee production and marketing increases the volume of coffee supplied to the market by $2.5 \%$; and 1 hectare increase in size of land covered by coffee increases the volume of coffee supplied to the market by $70.93 \%$.

\section{ACKNOWLEDGEEMENTS}

Southern Agricultural Research Institute deserves great acknowledgment for is financial support for this study. My dear fried Getachew Gudero also deserves great appreciation for his editorial support.

\section{REFERENCES}

Abiy T (2016). Assessments of Coffee Marketing Chain and Its Export Performance in Ethiopian GDP. M.Sc. Thesis, Addis Ababa University, Ethiopia

CSA (2013). Population Projection of Ethiopia for All Regions at District Level from 2014-2017.

CSA, World Bank (2013). Ethiopian Rural Socioeconomic Survey. Joshi B (2017). Willingness to Pay for Sustainable Coffee. The Case Study of CANGGU, BALI. M.Sc. thesis, University of Gent, valorous

Murphy M, Dowding TJ (2015). The Coffee Bean: A Value Chain and Sustainability Initiatives Analysis. The case of Ethiopia.

Panhuysen S, Pierrot J (2014). Coffee Barometer. Hivos, IUCN Nederland, Oxfam Novib, Solidaridad, and WWF.

Roldán P (2007). Coffee, Cooperation and Competition: A Comparative Study of Colombia and Vietnam

TECHNOSERVE (2017). Improving the Productivity and Sustainability of Smallholder Coffee Farmers in Guatemala. A Case Study of Techno Serve's coffee project in Sololá, Chimaltenango, and Sacatepéquez.

Tizazu T, Bosena T, Lema Z (2017). Determinants of Honey Market Supply: The Case of Shebedino District, Sidama Zone, SNNPR, Ethiopia. J. Econ. Sustain. Dev. 8(19):7-10.

http://www.sciencewebpublishing.net/jacr 


\section{APPENDIXES}

\section{Omitted variable test}

Ramsey RESET test using powers of the fitted values of Intotalproduction

Ho: model has no omitted variables

$F(3,36)=1.66$

Prob $>\mathrm{F}=0.1932$

\section{Hetero-scedasticity test}

Breusch-Pagan / Cook-Weisberg test for heteroskedasticity

Ho: Constant variance

Variables: fitted values of Intotalproduction

$\operatorname{chi} 2(1)=1.61$

Prob $>$ chi2 $=0.2038$

\section{Variance inflation factor}

\begin{tabular}{lcc}
\hline Variable & VIF & $\mathbf{1 / V I F}$ \\
\cline { 2 - 3 } Experience & 3.02 & 0.331592 \\
Family size & 2.77 & 0.360532 \\
Education & 2.23 & 0.448706 \\
No of extension contact & 1.87 & 0.535374 \\
Land covered by coffee & 1.78 & 0.563090 \\
Seed used & 1.75 & 0.570786 \\
Sex of the respondent & 1.70 & 0.587312 \\
Lag price & 1.40 & 0.716312 \\
Unit production cost (In) & 1.32 & 0.758478 \\
Credit use & 1.29 & 0.776908 \\
Mean VIF & 1.91 & \\
\hline
\end{tabular}

Source: survey, result, 2017/2018 